
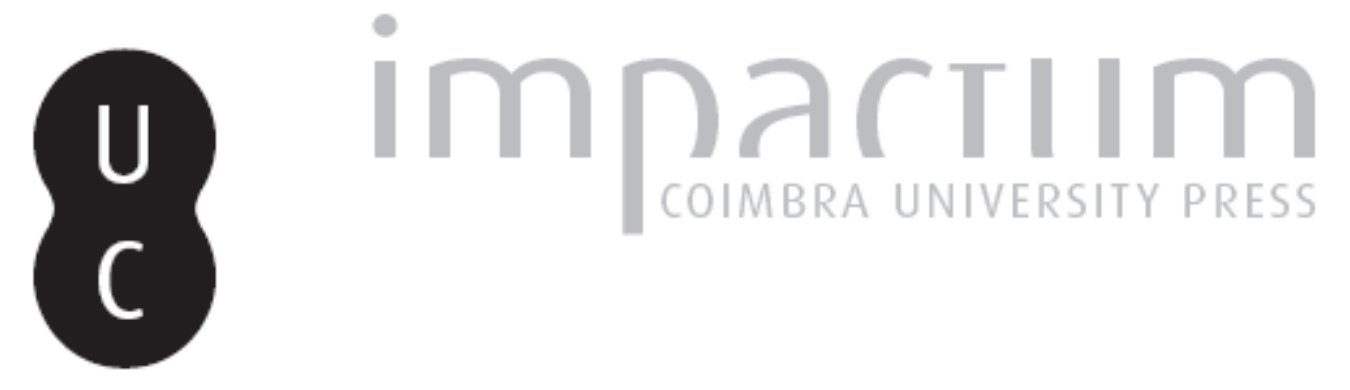

\title{
Estranhamentos: materialidades da escrita na Viena de 1900
}

Autor(es): $\quad$ Ribeiro, António Sousa

Publicado por: Centro de Literatura Portuguesa

URL persistente:

URI:http://hdl.handle.net/10316.2/29991

DOI:

DOI:http://dx.doi.org/10.14195/2182-8830_1-1_8

Accessed : $\quad$ 26-Apr-2023 10:51:42

A navegação consulta e descarregamento dos títulos inseridos nas Bibliotecas Digitais UC Digitalis, UC Pombalina e UC Impactum, pressupõem a aceitação plena e sem reservas dos Termos e Condições de Uso destas Bibliotecas Digitais, disponíveis em https://digitalis.uc.pt/pt-pt/termos.

Conforme exposto nos referidos Termos e Condições de Uso, o descarregamento de títulos de acesso restrito requer uma licença válida de autorização devendo o utilizador aceder ao(s) documento(s) a partir de um endereço de IP da instituição detentora da supramencionada licença.

Ao utilizador é apenas permitido o descarregamento para uso pessoal, pelo que o emprego do(s) título(s) descarregado(s) para outro fim, designadamente comercial, carece de autorização do respetivo autor ou editor da obra.

Na medida em que todas as obras da UC Digitalis se encontram protegidas pelo Código do Direito de Autor e Direitos Conexos e demais legislação aplicável, toda a cópia, parcial ou total, deste documento, nos casos em que é legalmente admitida, deverá conter ou fazer-se acompanhar por este aviso.

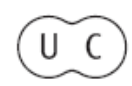




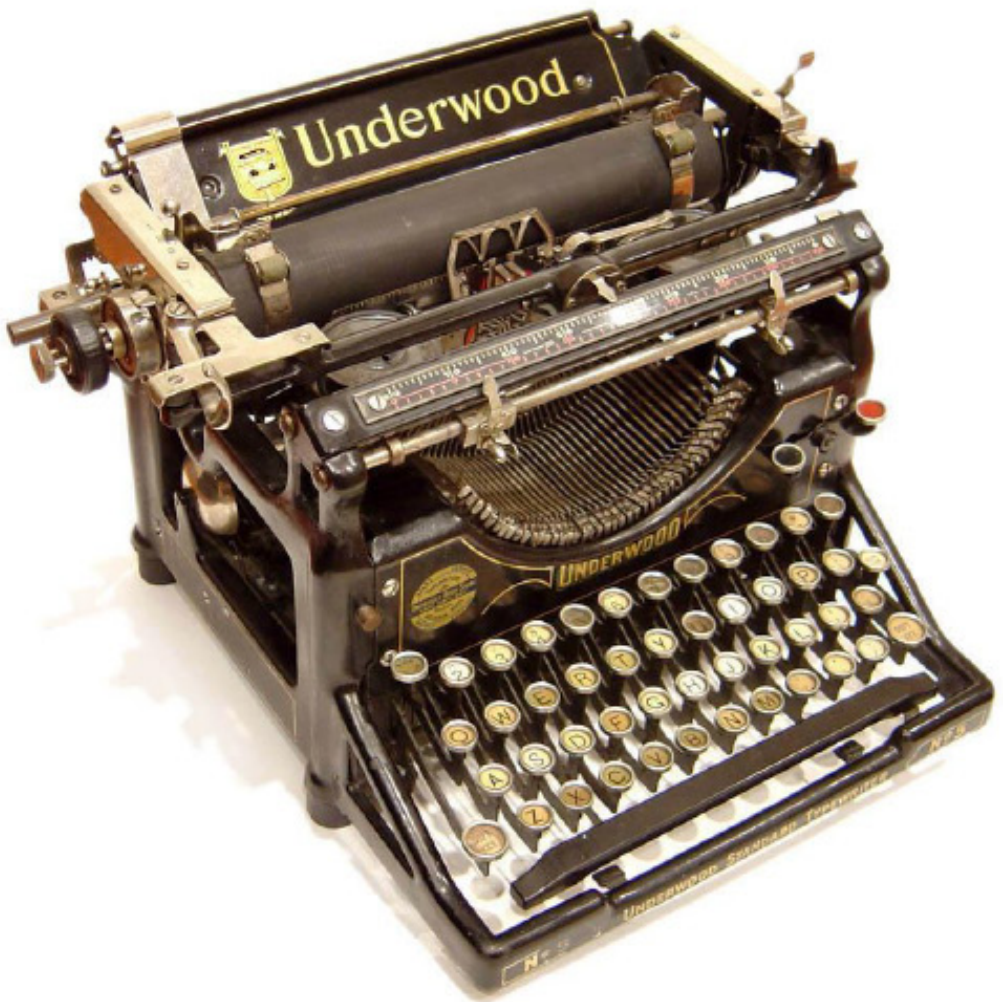

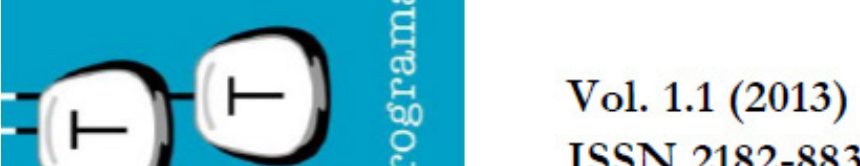

ISSN 2182-8830

'Estranhar Pessoa com

as Materialidades da Literatura'

Orgs. Manuel Portela \&

Osvaldo Manuel Silvestre 


\title{
Estranhamentos:
}

\section{Materialidades da Escrita na Viena de 1900 ANTÓNIO SOUSA RIBEIRO}

\author{
Universidade de Coimbra
}

Resumo

A partir de um conceito amplo de materialidades, percorrem-se alguns aspetos da modernidade vienense com vista a pôr em relevo dimensões da prática da escrita que oferecem paralelismos relevantes com a obra de Fernando Pessoa. Palavras-chave: Materialidades da Literatura; Fernando Pessoa; Viena de 1900; Karl Kraus; Hugo von Hofmannsthal.

Abstract

Using a broad notion of materialities, the article touches upon some aspects of Viennese modernity with the aim of highlighting several dimensions of the practice of writing that offer relevant parallels to the work of Fernando Pessoa. Keywords: Materialities of Literature; Fernando Pessoa; Vienna 1900; Karl Kraus, Hugo von Hofmannsthal.

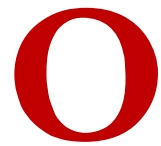

s gigantes como Pessoa, pelo descomunal da sua estatura, parecem sempre incomparáveis. Mas trata-se, evidentemente, de um erro de perspetiva. Para corrigir esse erro, tanto mais importante se torna explorar, não apenas os aspetos de receção e influência perseguidos por uma comparatística genética, mas, sobretudo, as dimensões paradigmáticas apenas acessíveis a uma comparatística tipológica. ${ }^{1}$ É assim que estranhar Pessoa significa também olhar a obra pessoana de uma perspetiva não apenas atenta à sua profunda originalidade, mas também às convergências que a relacionam com outras referências cimeiras do modernismo europeu. São algumas dessas convergências que procurarei iluminar sucintamente no presente artigo, através de uma abordagem de contextos porventura menos familiares, traduzida num percurso breve pela modernidade vienense centrado em particular, se bem que não em exclusivo, na figura de Karl Kraus.

Em estudos vários publicados esparsamente, tenho procurado abrir as portas a um trabalho comparatístico sobre os modernismos português e austríaco a partir da radicação num conceito de modernidade periférica ou excêntrica (Ribeiro, 1997; 2007; 2011). No presente artigo, pretendo prosseguir esta linha de reflexão usando como guião o conceito de

${ }^{1}$ Para este conceito, ver, entre outros, Zima, 1992: 94-129. 
materialidades. $\mathrm{O}$ espetro coberto por este conceito é, evidentemente, muito amplo. No âmbito do programa de doutoramento "Materialidades da Literatura", abstivemo-nos, julgo que sabiamente, do pathos da definição, evitando assim circunscrições necessariamente limitadoras. $\mathrm{Na}$ minha perspetiva, as materialidades da literatura são, antes de mais, as materialidades das relações sociais de que os textos constituem um modo particular de cristalização. A noção de Voloshinov/Bakhtine de que todo o enunciado deve ser entendido como elemento de uma interação social faz com que o sentido não possa ser concebido como algo simplesmente imanente, nem ao sujeito nem ao discurso, mas sim como sendo indissociável da materialidade dos signos captada no seio da dinâmica própria de uma relação de comunicação verbal que é sempre performativa (Voloshinov, 1973). É este conceito amplo de materialidades que me interessa em primeira linha, porque é dele que decorre, no fundo, tudo o resto, e é a partir deste conceito que irei deambular por alguns aspetos mais específicos do tema.

Começarei por lembrar o célebre e ultimamente muito glosado passo do Livro do Desassossego sobre "o ódio à ortografia sem ípsilon", porque "a ortografia também é gente" e "a palavra é completa vista e ouvida" (Pessoa, 1982: vol. 1, 17). Este passo assenta consabidamente no pressuposto de que, como se lê num outro fragmento hipoteticamente datado também de 1931, "[a]s palavras são [para mim] corpos tocáveis, sereias visíveis, sensualidades incorporadas" (Pessoa, 1982: vol. 1, 15). Detenhamo-nos por momentos nesta dimensão de materialidade, já que a noção de que a palavra só é completa "vista e ouvida" constitui ela própria um aspeto determinante da modernidade vienense. Num passo da conferência "A poesia e a vida", de 1896, o jovem Hofmannsthal lembrava, revelando o muito que aprendera com Mallarmé, que "o material da poesia são as palavras" (Hofmannsthal, 1979a: 15) ${ }^{2}$ e continuava definindo o poema como uma teia verbal e, enquanto tal, como uma figuração única capaz de arrancar as palavras às suas ligações "fixas" e "falsas" e de, colocando-as em movimento, gerar constelações insuspeitadas, inteiramente dependentes da dimensão do visível e do audível latente na materialidade do discurso. Aparentemente, o autor iria desdizer-se poucos anos mais tarde. Quem porventura tenha presente um texto como a célebre "Carta de Lord Chandos", do mesmo Hugo von Hofmannsthal, lembrar-se-á por certo da frase em que o suposto alter ego do autor expõe o drama de as palavras se lhe desfazerem na boca "como cogumelos podres" (Hofmannsthal, 1979b: 465). É verdade, o ceticismo sobre a linguagem de que o texto está impregnado parece apontar, justamente, para uma noção de perda da materialidade e de insubstancialidade da linguagem. Mas uma tal leitura é demasiado apressada, já que ignora um aspeto determinante, aquilo a que tenho chamado o paradoxo performativo deste texto central da modernidade europeia, escrito em 1902 (Ribeiro, 2011;

${ }^{2}$ Todas as traduções são minhas. 
cf. também Martins, 2013). Na verdade, frases como a citada e a tónica geral de ceticismo em relação à linguagem articulada no ensaio vão de par com uma estrutura retórica extremamente elaborada: a personagem declara ter perdido qualquer noção da substancialidade da linguagem usando um discurso densamente articulado, em que a precisão das imagens e dos conceitos e o rigor da auto-análise sublinham à saciedade o caráter de encenação ficcional que define a composição de um texto que é tudo menos confessional. Como tantas outras personagens das ficções da modernidade, Chandos está imerso num labirinto visto, simultaneamente, como um espaço de perda e um lugar de identificação do eu. A errância a que o sujeito é condenado pela perda das palavras, definidas, num passo central da "Carta", como vórtices vertiginosos através das quais se vai dar ao vazio (Hofmannsthal, 1979b: 466), encontra, a meu ver, o equivalente estrutural naquele "poço sem muros, mas com a viscosidade dos muros, o centro de tudo com o nada à roda" que constitui uma das mais marcantes autodefinições do semi-heterónimo pessoano (Pessoa, 1982: vol. 1, 31). A "Carta" de Hofmannsthal é, desta perspetiva, um texto fundamente experimental, um ensaio em torno da mesma geometria do abismo que fornece as coordenadas labirínticas ao percurso de Bernardo Soares. Não haverá senão concluir que, em vez do alter ego que as leituras biografistas muito tempo dominantes quiseram ver na figura de Lord Chandos, ele é, na verdade, muito mais um heterónimo, enquanto personagem de um drama em gente que, na obra de Hofmannsthal surge apenas esboçado aqui e ali, muito longe da consumação pessoana, mas partilhando, mesmo assim, o mesmo gesto performativo.

Também a definição da linguagem por Karl Kraus como "a única quimera cujo poder de ilusão é infinito" (Die Fackel 885-887, 1932: 4)3 está muito longe de traduzir uma crença mística ou uma conceção metafísica. Pelo contrário, toda a obra de Kraus assenta numa prática do discurso para a qual a noção de materialidade é central. Alguns paralelos diretos com Pessoa saltam mesmo à vista: assim, por exemplo, o pathos da recusa pessoana da ortografia sem ípsilon tem uma correspondência muito próxima no autor vienense. O poema "Elegia à morte de um som", publicado em 1915 (F413417: 107-10), lamenta, em registo nostálgico, uma das medidas da reforma ortográfica de 1901 no espaço de língua alemã, que ditara a queda do h átono que anteriormente se escrevia depois do $\mathrm{t}$ em muitas palavras. Não faria sentido alongar-me aqui sobre a técnica intrincada deste relativamente longo poema, que restitui $\mathrm{o}$ h eliminado nalgumas palavras de forte ressonância poética (como "Thau", orvalho, ou "Morgenathem", sopro da manhã) e o omite em casos em que a reforma ortográfica o mantivera, por exemplo, antes de $1, \mathrm{~m}$ ou $\mathrm{n}$, acabando por produzir um texto que de todo em todo não

${ }^{3}$ Os textos da revista Die Fackel serão doravante citados apenas com a inicial F e a menção do número e data de publicação. 
é inteligível sem a dimensão visual. O título do poema, recordo, é "Elegia à morte de um som" e não, por exemplo, "de uma letra". Como, relembro ainda, o " $\mathrm{h}$ " em questão é átono, a forma do título, reivindicando um valor fonético na verdade inexistente, redunda num pôr em primeiro plano da materialidade da palavra na página, gerando uma peculiar dialética entre a palavra ouvida e a palavra vista:

\title{
Elegie auf den Tod eines Lautes
}

\author{
Weht Morgenathem an die Fruhjahrsbluthe, \\ so siehst du Thau. \\ $\mathrm{DaB}$ Gott der Sprache dieses $\mathrm{h}$ behüte! \\ Der Reif ist rauh.
}

\author{
Wie haucht der werthe Laut den Thau zu Perlen \\ in Geistes Strahl. \\ Sie vor die Sau zu werfen, diesen Kerlen \\ ist es egal.
}

Kein Wort darf Seele haben, der Barbare

er lebt so auch.

Sein Stral ist Strafe, Wort ist Fertigware

zum Sprachgebrauch.

Ein jeder Wirth ist, hat er etwas Grutze,

am Wort ein Wirt.

Die Sprache ist ja als der Hausfrau Stütze

nur engagiert.

Sie streckt sich nach der Decke, keines Falles

sie Aufwand treibt.

Sie kriegt, da sie ja Mädchen nur für Alles, was übrig bleibt.

Man ist kurz angebunden, wenn man praktisch so mit ihr spricht.

Dann aber wird ihr noch die Notzucht faktisch von jedem Wicht.

Der Orthograph kennt Muth nicht, hat nur Mut

vor einem Laut,

den vorschriftsmäBig er mit wilder Wut

zusammenhant.

O essencial da obra de Kraus está na revista Die Fackel, O Archote, que publicou durante 37 anos, de 1899 a 1936, e da qual, a partir de 1911, foi o único autor. $\mathrm{O}$ total são cerca de 23000 páginas, compondo um universo denso a que poderia chamar-se com propriedade um macrotexto, uma vez que, apesar da autonomia de cada peça em particular, existem múltiplos fios a dar uma forte coerência ao conjunto. A importância que o autor confere à dimensão visual é bem demonstrada pelo cuidado posto na composição da revista (Figura 1). Como, de muitas páginas, estão conservadas as provas tipográficas, normalmente não menos de 10 provas sucessivas - Kraus trabalhava sobre o texto impresso, que reescrevia ou, talvez melhor, 
recompunha ad infinitum (Figura 2) -, é possível reconstruir esse processo, verificando, por exemplo, que, muitas vezes, na fase final da produção, o autor não hesitava em alterar ou em mandar compor de novo o texto se não o satisfazia o aspeto visual da página e queria que a transição para a página seguinte se fizesse num ponto diferente. Isto é, cada página era tratada como um bloco que tinha de ter uma coerência tipográfica própria.

\section{DIE FACKEL

$\begin{array}{lll}\text { Nr. 406-412 } & \text { 5. OKTOBER } 1915 & \text { XVII. JAHR }\end{array}$

\begin{tabular}{|c|c|}
\hline \multicolumn{2}{|c|}{ Zwei Stimmen } \\
\hline & \\
\hline & .. Und die $\mathrm{F}$ ische, \\
\hline & \\
\hline en Vate & nen der Adria haben \\
\hline & itengebabtv \\
\hline & In der südlichen Adria \\
\hline & $\begin{array}{l}\text { speisten sie fast die } \\
\text { ganze Bemannung des }\end{array}$ \\
\hline & ,Leon Gambetta'. Die \\
\hline & Bewohner der mittleren \\
\hline & $\begin{array}{l}\text { Adria fanden Lebens- } \\
\text { unterhalt an jenen }\end{array}$ \\
\hline & $\begin{array}{l}\text { It a lienern, die wir } \\
\text { von dem Fahrzeug ,Tur- } \\
\text { bine" nicht mehr retten }\end{array}$ \\
\hline & $\begin{array}{l}\text { konnten, und in der } \\
\text { nördlichen Adria wird }\end{array}$ \\
\hline & $\begin{array}{l}\text { deneeresbewohnern } \\
\text { der Tisch immer } \\
\text { reichlicher gedeckt. }\end{array}$ \\
\hline $\begin{array}{l}\text { gt } \\
\text { en }\end{array}$ & $\begin{array}{l}\text { Dem Unterseeboot } \\
\text { dusa } \\
\text { und }\end{array}$ \\
\hline & $\begin{array}{l}\text { Torpedobooten hat sich } \\
\text { jetzt der Panzerkreuzer }\end{array}$ \\
\hline & $\begin{array}{ll}\text { lalfic zugesellt. } & \text { Die } \\
\text { sterkollektion } & \text { der }\end{array}$ \\
\hline & $\begin{array}{l}\text { maritimen A u b bute } \\
\text { die sich bisher auf da }\end{array}$ \\
\hline
\end{tabular}

Figura 1. "Duas vozes: Vaticano: a prece de Bento; Redação: o ditado de Bento [Moritz Benedikt, diretor do jornal Neue Freie Presse]." 


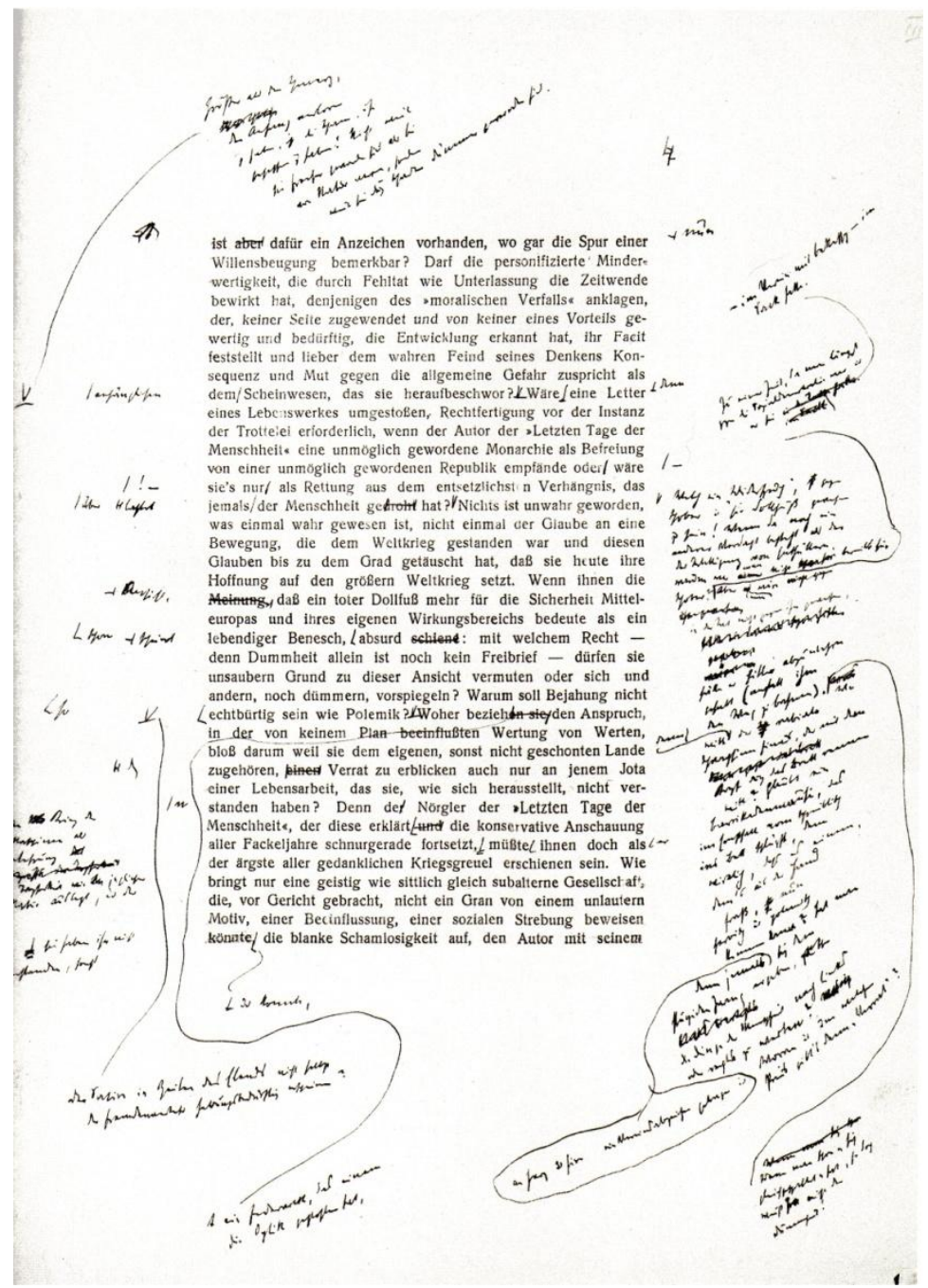

Figura 2. Prova tipográfica de uma página do último texto publicado em Die Fackel ("Wichtiges von Wichten (In verständlicher Sprache)", F917-922, 1936: 94-112). As correções e acrescentos estão ainda muito longe do que virá a ser a versão final.

Por vezes ainda, o processo de escrita assenta numa técnica de montagem ou de colagem, como é sobretudo o caso das glosas satíricas em que Kraus cola no seu manuscrito recortes de jornal ou de outras proveniências em torno dos quais desenvolve o seu próprio discurso. Em múltiplos aforismos, o autor reflete sobre o seu processo de produção, enquanto confronto agónico com um material verbal que lhe resiste. Veja-se, por exemplo: 
O meu embaraço vai crescendo à medida que o que escrevo se aproxima da forma definitiva. Quanto mais me aproximo de uma palavra, tanto mais ela sangra, como o cadáver ante o assassino. Não me poupo a este ordálio e cubro as margens de uma prova tipográfica, talvez precedida por quinze outras corrigidas despreocupadamente, com sinais que são como chagas. Tenho sempre pelo menos dois caminhos e o melhor seria seguir por ambos e por todos. Ainda um dia hei-de resolver-me a apresentar a frase em versões diferentes, para benefício do leitor, que assim será forçado a ler uma frase várias vezes, e para afastar mais aqueles que só andam à cata de opiniões. [...] (Kraus, 1988: 18)

Ou ainda:

Quando já não consigo continuar, é porque dei com a cabeça na parede da linguagem. Retiro-me então, com a cabeça a sangrar. E gostaria de seguir em frente. (Kraus, 1988: 17)

A linguagem como parede é uma imagem que remete para uma noção de materialidade que, como vimos, inclui também decisivamente a dimensão visual. $\mathrm{Na}$ verdade, para Kraus, a materialidade da palavra na página só é indiferente para aqueles que, como se lê num passo do poema "Elegia à morte de um som", vêem a palavra como "artigo pronto a usar", isto é, têm uma conceção puramente instrumental do discurso. Em contrapartida, para o artista da palavra, aquele para quem, para relembrar Bernardo Soares, a palavra "é completa vista ou ouvida", a reforma ortográfica provoca perdas que são irreparáveis e que justificam amplamente a reflexão no modo elegíaco.

É a conceção não-instrumental do discurso e a definição correlativa da produção textual como um modo de composição fundamentalmente artesanal que fundamenta a suspeita em relação a modernas tecnologias da escrita vistas como instrumento de mecanização da linguagem. A máquina de escrever, a pessoana máquina triunfal, é, em Kraus, mantida à distância. Trata-se de um objeto muito poucas vezes referido nas 23000 páginas que referi há pouco e que só em dois casos - caracteristicamente, dois aforismos - é motivo de uma reflexão mais aprofundada. No primeiro caso, a reflexão faz-se no modo satírico, através de uma técnica de inversão que remete para a confusão entre meios e fins própria das conceções instrumentais do discurso:

Era uma vez uma máquina de escrever que tinha um escritor, mas não conseguiu suportar os custos de manutenção. (F266, 1908: 23)

Num segundo caso, a reflexão versa diretamente sobre o processo de escrita:

Um aforismo não pode ditar-se para uma máquina de escrever. Levaria demasiado tempo. (F266, 1908: 25) 
Note-se a ambiguidade da formulação. O que é que leva demasiado tempo - o ditado ou a escrita? Ambas as leituras são possíveis e o texto vive dessa ambivalência: o tempo de composição de um aforismo é demasiado longo para poder ser conciliável com o recurso à datilografia, mas, por outro lado, o aforismo representa a materialização de uma fulguração de sentido em relação com a qual o tempo da escrita à máquina é demasiado lento. Em qualquer dos casos, o processo de escrita possui uma lógica própria que é desconforme relativamente à regularidade mecânica pressuposta pela figura da máquina de escrever.

O pressuposto de que "a palavra é completa vista e ouvida" foi tomado por Kraus muito à letra também noutras dimensões. Num aforismo de finais de 1913, ele reivindica para si ser "talvez o primeiro caso de um escritor que vive a escrita ao mesmo tempo como um ator" (F389-90, 1913: 42). Para entender esta asserção quase programática, é necessário ter presentes as características distintivas da sátira krausiana. No ensaio "Karl Kraus, escola de resistência”, Elias Canetti observou que um dos maiores paradoxos dessa sátira consistia no facto de que

este homem que desprezava tanta coisa, que, logo a seguir a Quevedo e Swift, era o desprezador mais implacável da literatura universal, uma espécie de flagelo de Deus para o ser humano pecador, dava a palavra a todos. Não estava disposto a sacrificar a voz mais mesquinha, mais insignificante, mais oca. (Canetti, 1981: 46).

$\mathrm{Na}$ verdade, a conceção do senso comum que vê o modo satírico como essencialmente monológico, dominado pela autoridade da vOz singular de um moralista incorruptível, está longe de adequada. Para ser eficaz, a autoridade da voz satírica tem de se afirmar, não no terreno abstrato das ideias e dos princípios, mas sim no campo da confrontação concreta com os enunciados múltiplos que compõem o discurso público da época. É assim que, na tradição da sátira menipeia teorizada por Bakhtine, a sátira krausiana está cheia de vozes, é intrinsecamente dialógica. Isto implica que o uso constante do material da citação não cumpra simplesmente uma função documental, antes, mais do que isso, tenha uma função profundamente dramática, no sentido em que oferece ao discurso krausiano uma estrutura dinâmica contrapontística assente no confronto entre vozes conflituantes que tem mais que ver com o teatro do que com as convenções do discurso ensaístico. A abordagem da cena da escrita pelo autor satírico assume, assim, um caráter essencialmente performativo, no sentido em que os seus usos da linguagem não assentam no pressuposto de um sentido pré-estabelecido, mas antes da dinâmica dialógica, polifónica, de um espaço discursivo estruturado como uma câmara de eco plena das reverberações de muitas outras vozes. Estamos, pois, em pleno perante uma "Materialästhetik", uma estética do material, na aceção pós-hermenêutica por exemplo de um Benjamin, de acordo com a 
qual a dimensão estética está inerradicavelmente associada ao uso de um material que é sempre já pré-estruturado.

Conceitos como o de vOz ou entoação, centrais à estética performativa da sátira krausiana, traduzem uma conceção gestual do discurso que teria amplas consequências. Basta lembrar a centralidade do conceito de "Gestus", de "gesto", na estética teatral brechtiana. Ou o conceito de "máscara acústica", que permite definir a personagem através de um gesto verbal próprio, formulado por Elias Canetti e subjacente à técnica compositiva não apenas dos seus dramas, mas também do seu romance Die Blendung, Auto de fé. É assim que o postulado da natureza antiteatral do modernismo, tal como é expresso, por exemplo, por Toril Moi (2004) tem de ser relativizado. $\mathrm{Na}$ verdade, se o caráter estático do drama modernista pode, à primeira vista, justificar esse postulado, não é menos certo que a exploração da materialidade da palavra na cena da escrita modernista conduz à forte acentuação de uma conceção performativa do discurso na linha do que atrás fui expondo.

No caso de Kraus, o pressuposto de uma vivência histriónica do discurso produziu consequências também noutro plano de grande importância, o de um teatro da palavra materializado nas 700 sessões públicas de leitura que protagonizou, não apenas em Viena, mas em muitas outras cidades do espaço de língua alemã e mesmo fora deste, em Praga ou Paris, por exemplo. Não se trata apenas da prática, ainda hoje corrente, embora não muito entre nós, de sessões de leitura pelo autor normalmente como forma de promoção de um livro recém-publicado. Trata-se de um modo de reprodução, que afirma a importância da voz, da "palavra ouvida" como elemento constitutivo do processo de produção de sentido. Nas sessões que realiza, normalmente em salas de teatro, algumas de grande dimensão, para públicos que podem chegar às mil pessoas, Kraus não se limita a ler textos próprios, lê também outros autores, à cabeça Shakespeare, montando uma cena verbal intensamente polifónica muito no sentido do que Pasolini viria a propor como "Teatro di parola".

Mas há em Kraus ainda outras dimensões de uma conceção ampla da materialidade do discurso. Destaco o uso da imagem fotográfica. Kraus foi um dos pioneiros do uso da fotomontagem no espaço de língua alemã e usa diversas vezes a fotografia, não como ilustração, mas sim como elemento constitutivo da cena satírica (Figura 3). Este aspeto é levado ao extremo na última cena do drama monumental Os Últimos Dias da Humanidade. Trata-se de uma cena apocalíptica na qual, ante a iminência da derrota, oficiais de alta patente dos exércitos coligados alemão e austro-húngaro se entregam a excessos orgíacos, numa contrafação parodística da cena do banquete de Nabucodonosor. Na parede, em vez das palavras ominosas da matriz bíblica, surgem em sequência visões fantasmagóricas que, de um modo reminiscente dos pesadelos que atormentam Ricardo III na véspera da batalha fatídica, vão fazendo desfilar algumas das vítimas inocentes da guerra, que regressam para 
exigir a punição dos algozes. No plano da encenação, a sucessão destas visões não poderia ser realizada senão através da projeção de imagens ou de fragmentos fílmicos, acrescentando um componente visual que não tem uma função simplesmente aditiva, e muito menos decorativa, antes faz parte integral do discurso dramático, ao qual confere uma dimensão insubstituivelmente complexa.

\section{DER SIEGER}

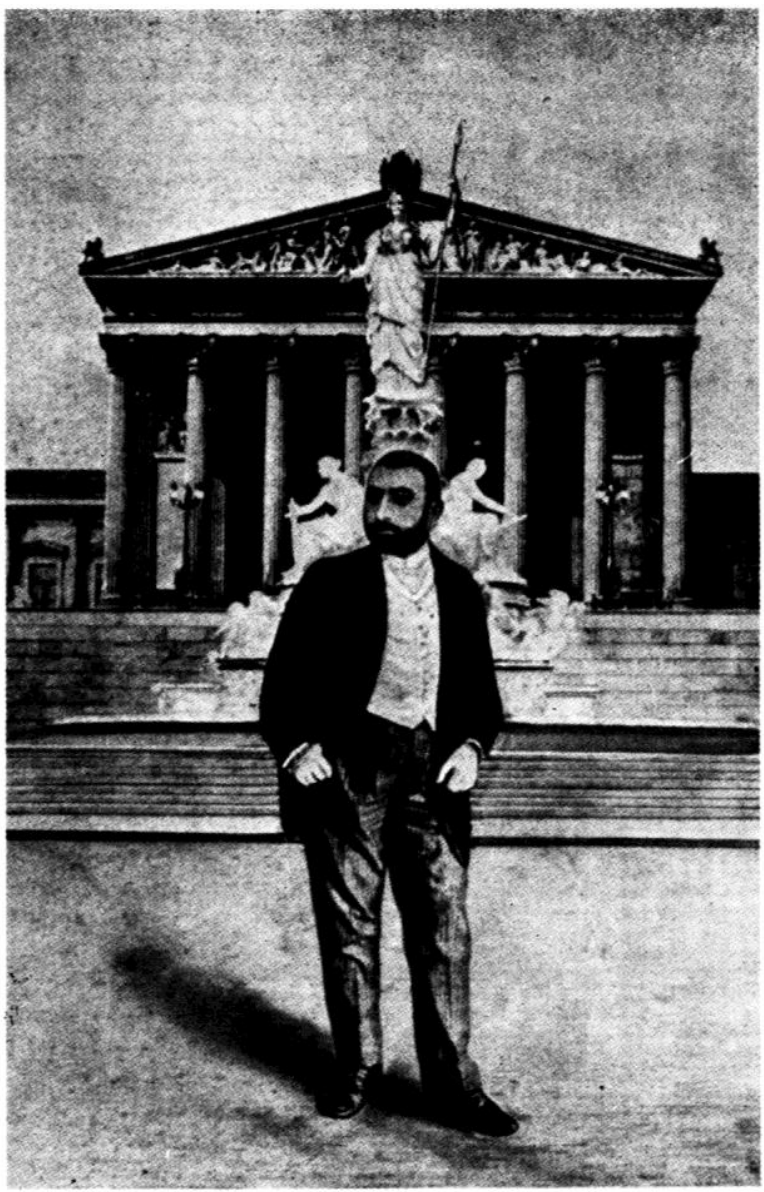

Nach einer photogr. Aufnahme

\section{DER HERAUSGEBER DER NEUEN FREIEN PRESSE}

20. JUNI 1911

Figura 3. "Der Sieger", "O vencedor", F326-328. Uma fotografia de Moritz Benedikt, director do jornal Neue Freie Presse, um dos grandes alvos satíricos de Kraus, montada sobre uma fotografia do edifício do Parlamento austríaco, de modo a que a estátua de Pallas Atena parece nascer da cabeça do jornalista. O título da fotomontagem refere-se ao resultado das eleições recém-realizadas - a vitória é antes de mais da imprensa. 


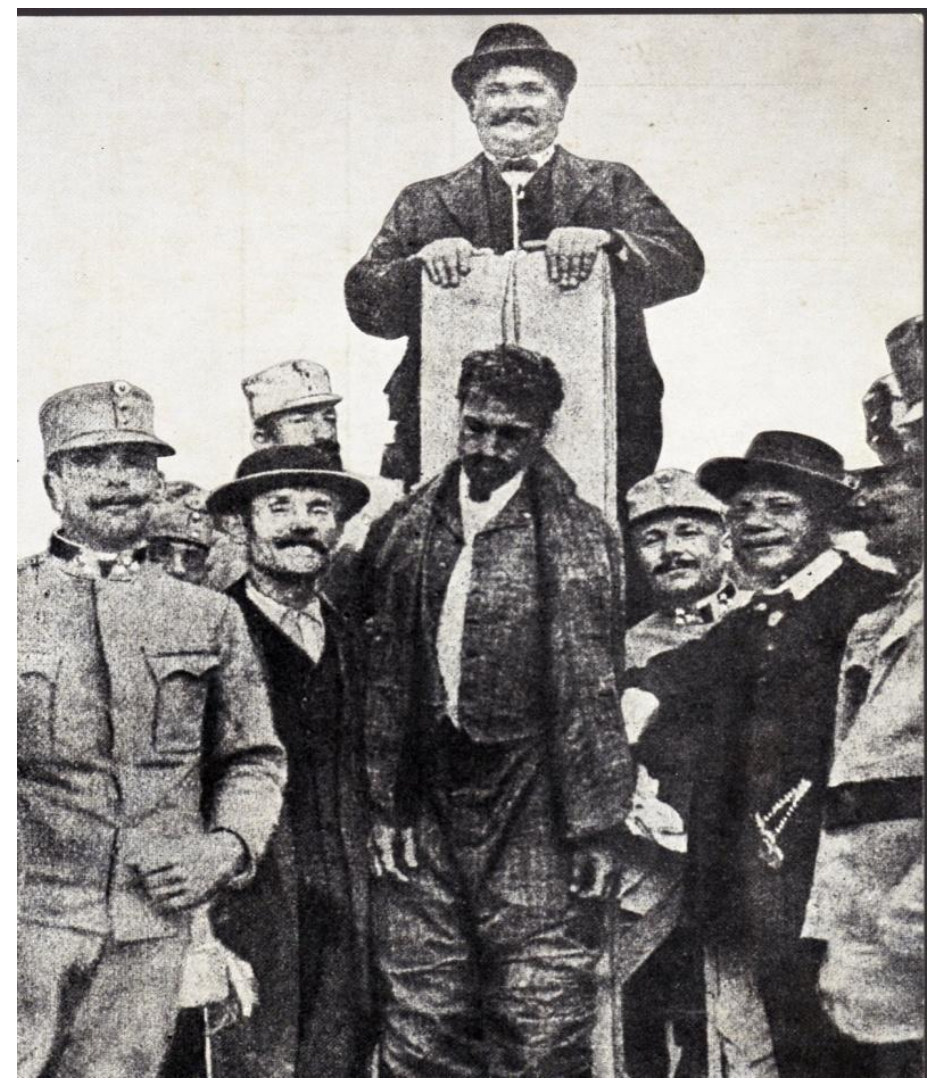

Figura 4. A fotografia da execução de Cesare Battisti, nacionalista italiano deputado ao Parlamento austríaco que se alistou no exército italiano e, capturado em combate, foi condenado em processo sumário, circulou na época como postal ilustrado e faz parte integrante da tragédia Os Últimos Dias da Humanidade. A expressão comprazida do carrasco e dos circunstantes representa, para Kraus, o epítome do "rosto austríaco", protótipo do que Hannah Arendt viria a designar como a "banalidade do mal".

Chegados aqui, poderá perguntar-se com legitimidade, mas o que é que tudo isto tem que ver com Pessoa? Tinha esperança, ao conceber este estudo exploratório, de conseguir responder a essa pergunta e julgo que fui fornecendo, senão respostas, pelo menos elementos de resposta. Mas regresso brevemente, e para concluir, um pouco atrás. O pressuposto de que um estado de alma é uma paisagem, afirmado por Bernardo Soares contra a "insuportável interiorice" da frase de Amiel "a paisagem é um estado de alma", implica, ao afirmar não "a mentira de uma teoria, mas tão-somente a verdade de uma metáfora” (Pessoa, 1982: vol. 1, 103), que a materialidade da imagem surja no fio do discurso dotada de um peso específico, como um elemento autónomo, assente numa lógica não de ornamentação ou de 
reforço retórico, mas de distanciamento interruptivo e, portanto, abrindo um espaço anti-psicologístico que é mais da esfera do mostrar do que do dizer. Por outras palavras, a imagem constitui-se como um núcleo ou motivo cénico que permite a organização do discurso num sentido não simplesmente linear e sequencial, mas de um modo que se aproxima da ideia de montagem.

Dou um único exemplo, uma das imagens captadas por Bernardo Soares ao acaso das suas deambulações de flâneur: "E todos como enguias num alguidar se enrolam entre eles e se cruzam uns acima dos outros e nem sabem dos alguidares" (Pessoa, 1982: vol. 1, 133). A exterioridade radical deste instantâneo arrancado ao fluir das imagens da cidade produz um efeito de singularização que está muito próximo da iluminação profana benjaminiana enquanto momento de uma dialética em estado de repouso, isto é, enquanto interrupção tensa de um fluxo e núcleo de uma explosão de sentido. São imagens marcadas, como esta, por uma absoluta estranheza que estão frequentemente no cerne da narrativa kafkiana. E, por sua vez, também a "iluminação instantânea de uma paisagem anímica" louvada por Kraus em certo motivo shakespeariano (F349-350, 1912: 10) se alimenta do mesmo princípio de uma materialidade do discurso baseada numa lógica de apresentação cénica.

Kafka, Kraus, Pessoa, Hofmannsthal... Julgo que, em torno de questões como as que aflorei da perspetiva das materialidades da literatura, é possível detetar cruzamentos e convergências que apontam para dimensões e tipologias da escrita modernista com evidente significado paradigmático. Limiteime aqui a apontar sumariamente alguns dos vetores dessas confluências, que será necessário explorar de modo muito mais sistemático. ${ }^{4}$

\section{Referências}

CANETTI, Elias (1981). "Karl Kraus, Schule des Widerstands", in E. Canetti, Das Gewissen der Worte. Essays. Frankfurt am Main: Fischer, 4253.

HOFMANNSTHAL, Hugo von (1979a). "Poesie und Leben", in Reden und Aufsätze. Org. Bernd Schoeller. Frankfurt am Main: Fischer, 13-19. (1979b). "Ein Brief', in Erzäblungen, erfundene Gespräche und Briefe, Reisen. Org. Bernd Schoeller. Frankfurt am Main: Fischer, 461-72.

KRAUS, Karl (1988). O Apocalipse Estável. Aforismos. Seleção, tradução e posfácio de António Sousa Ribeiro. Lisboa: Apáginastantas.

4 Artigo produzido no âmbito do projeto de investigação 'Nenhum Problema Tem Solução: Um Arquivo Digital do Livro do Desassossego' (referência PTDC/CLELLI/118713/2010), do Centro de Literatura Portuguesa da Universidade de Coimbra. Projeto financiado pela FCT e cofinanciado pelo FEDER, através do Eixo I do Programa Operacional Fatores de Competitividade (POFC) do QREN, COMPETE: FCOMP-01-0124-FEDER-019715. 
MARTINS, Catarina (2013). "Para lá da representação? Repensar a violência na prosa ensaística de expressão alemã do início do século XX", in António Sousa Ribeiro (org.), Representações da Violência. Coimbra: Almedina, 65-81.

MOI, Toril (2004). "Ibsen, Theatre, and the Ideology of Modernism", Theatre Survey, 45(2), 247-52.

PESSOA, Fernando (1982). Livro do Desassossego por Bernardo Soares. Org. Jacinto do Prado Coelho. Lisboa: Ática.

RIBEIRO, António Sousa (1997). "Metamorphoses of the Flâneur: From Ringstrasse to Rua dos Douradores", New Comparison, 21, 65-77. (2007). "A Center that Can Hold. The Figure of Empire in Portuguese and Austrian Modernism", in Vivian Liska e Astradur Eysteinsson (orgs.), Modernism. Amsterdam: John Benjamins, 561-72. (2011). "Modernist Confluences: Comparative Perspectives on Portuguese Modernism", in Steffen Dix e Jerónimo Pizarro (orgs.), Portuguese Modernisms. Multiple Perspectives on Literature and the Visual Arts. London: Legenda, 250-63.

VOLOSHINOV, V. N. (1973). Marxism and the Philosophy of Language. Transl. Ladislav Matejka and I. R. Titunik. Ney York / London: seminar Press [11929].

ZIMA, Peter V. (1992). Komparatistik. Einführung in die Vergleichende Literaturwissenschaft. Tübingen: Francke. 